\title{
The Effect of Peripherin/rds Haploinsufficiency on Rod and Cone Photoreceptors
}

\author{
Tong Cheng, ${ }^{1}$ Neal S. Peachey, ${ }^{3,4}$ Shihong Li, ${ }^{2}$ Yoshinobu Goto, ${ }^{3,4}$ Yun Cao, ${ }^{2}$ and Muna I. Naash ${ }^{1,2}$ \\ Departments of ${ }^{1}$ Genetics and ${ }^{2}$ Ophthalmology and Visual Sciences, University of Illinois at Chicago, College of Medicine, \\ Chicago, Illinois 60612, 3Hines Veterans Affairs Hospital, Hines, Illinois 60141, and ${ }^{4}$ Department of Neurology, Stritch \\ School of Medicine, Loyola University of Chicago, Maywood, Illinois 60153
}

Haploinsufficiency because of a null mutation in the gene encoding peripherin/rds has been thought to be the primary defect associated with the photoreceptor degeneration seen in the retinal degeneration slow (rds) mouse. We have compared the effects of this haploinsufficiency on rod and cone photoreceptors by measuring the levels of rod- and cone-specific gene expression, by determining the relative rates of rod and cone degeneration, and by electroretinography. These analyses were performed at ages before and after the onset of degeneration of the photoreceptor cells. The data were consistent in demonstrating that measures for cone photoreceptors are relatively spared in comparison to comparable measures for rod photoreceptors. Blue cones were retained in higher number than $\mathrm{red} / \mathrm{green}$ cones for the first 3 months of the degeneration. Our results indicate that the haploinsufficiency present in $\mathrm{rds} /+$ mice has a greater impact on the rod than on the cone photoreceptor, a finding that likely reflects the tight regulation of peripherin/rds and the need for two functional alleles to assemble the structure of the rod outer segment and/or differences between the ultrastructure of the rod and cone outer segments.

Key words: photoreceptors; retinal degeneration; outer segment; electroretinograms; peripherin/rds
The retinal degeneration slow ( $r d s)$ mouse line has provided an important model for the study of photoreceptor degeneration since its initial description (Van Nie et al., 1978). Because the degenerative process is extremely slow, the $r d s$ mutation originally was thought to be an autosomal recessive trait. As a result, the defect has been studied primarily in $r d s / r d s$ mice, which display an abnormal development and subsequent degeneration of the photoreceptors (for review, see Molday, 1994). However, the $r d s$ phenotype is actually a semidominant trait characterized by haploinsufficiency in $r d s /+$ animals (Wilkie, 1994), in which the gene product from the one functional allele is inadequate to support normal function. The defect underlying the $r d s$ trait involves the insertion of a $9.2 \mathrm{~kb}$ repetitive genomic element within exon 2 of the peripherin/rds gene (Travis et al., 1989; Ma et al., 1995). Molday (1994) suggested that the $r d s$ mutation might produce a null allele by generating an unstable molecule. Consistent with this idea, $r d s /+$ mice exhibit a progressive photoreceptor degeneration that is more gradual than that seen in $r d s / r d s$ mice yet is characterized by abnormal outer segments and a gradual loss of cells in the outer nuclear layer (ONL; Hawkins et al., 1985; Sanyal et al., 1986).

The outer segments of vertebrate rod and cone photoreceptor cells consist of an ordered array of membranous disks. In rods,

\footnotetext{
Received July 15, 1997; revised Aug. 5, 1997; accepted Aug. 11, 1997.

This work was supported by the National Eye Institute (EY-10609 and EY-01792), the Foundation Fighting Blindness, Baltimore, MD, the Illinois Society to Prevent Blindness, the Knights Templar Eye Foundation, Springfield, IL, an unrestricted award from Research to Prevent Blindness, New York, NY, and the Department of Veterans Affairs. We thank Drs. Neeraj Agarwal, Donald Hood, Robert S. Molday, and Jeremy Nathans for generously providing, respectively, $r d s / r d s$ mice, MatLab programs, mAb 1D4, and antibodies against human blue and red/green pigments. We also thank Dr. Muayyad Al-Ubaidi for helpful comments on this manuscript. Correspondence should be addressed to Dr. Muna I. Naash, University of Illinois at Chicago Eye Center (m/c 648), 1855 West Taylor Street, Chicago, IL 60612.

Dr. Y Goto's present address: Neurological Institute, Kyushu University 60, Fukuoka 812 Japan.

Copyright (C) 1997 Society for Neuroscience $\quad 0270-6474 / 97 / 178118-11 \$ 05.00 / 0$
}

except for a few nascent disks at the base of the outer segment, the disks are surrounded by a separate plasma membrane. In cones, outer segment disks appear as a folded system of membranes that are continuous with each other and with the plasma membrane. Despite these structural differences, rod and cone disks are shed continuously and resynthesized. Peripherin/rds, a transmembrane glycoprotein, has been localized along the rim of mature disks as well as in the basal regions adjacent to the cilia of rod and cone outer segments where disk morphogenesis occurs (Molday, 1994). The absence of peripherin/rds in the $r d s / r d s$ mouse prevents normal development of the photoreceptor outer segment, leading to cell death. Although outer segment membrane biogenesis occurs in the $r d s / r d s$ mutant, the membrane is unable to fold into the proper disk structure. This indicates that peripherin/rds, probably in conjunction with other photoreceptor proteins, plays an important role in the assembly, orientation, and physical stability of the photoreceptor outer segment disk (Travis and Bok, 1993; Molday, 1994).

Because of the predominance of rods in the mouse retina (Carter-Dawson and LaVail, 1979), attention has focused primarily on the characteristics of rod, but not cone, degeneration in mice carrying the $r d s$ trait. Nevertheless, peripherin/rds mutations compromise cone-mediated function to different degrees (Farrar et al., 1991; Kajiwara et al., 1991, 1993; Nichols et al., 1993a,b; Wells et al., 1993). In light of this, we have performed a series of studies on $r d s /+$ mice to compare rod and cone involvement at structural and functional levels. The data indicate that the $r d s$ defect is more deleterious to rods than to cones, a difference that is likely to reflect a greater role of peripherin/rds in maintaining the structure of the rod outer segment. The data also provide an empirical basis with which to compare $r d s /+$ mice to patients heterozygous for one or another dominantly inherited peripherin/rds mutation. 


\section{MATERIALS AND METHODS}

rds mice. The gene defect of $r d s / r d s$ mice was moved first onto a pigmented background (C57BL/6) by continuous mating to normal C57BL/6 mice. The mice studied here were generated from the subsequent mating of $r d s /+$ to normal $(+/+)$ mice. The $r d s$ defect was inherited as a Mendelian trait so that approximately one-half of the offspring were $+/+$, and one-half were $r d s /+$. Mice were screened for the presence of the $r d s$ mutation by PCR amplification, using two primers: MIN 101 (5'-ATACTGCCTCCAACCTTC-3') from the peripherin/rds coding region and MIN 99 (5'- AGCCCAGATTGCCTGTGGCA-3') from the inserted element (Travis et al., 1989). All of the mice studied here were maintained in the breeding colony under cyclic light $(12 \mathrm{hr}$ light $/ 12 \mathrm{hr}$ dark) conditions; cage illumination was $\sim 7$ foot-candles during the light cycle. All procedures were approved by the local Institutional Animal Care and Use Committees and adhered to the Association for Research in Vision Ophthalmology (ARVO) Statement for the Use of Animals in Ophthalmic and Vision Research.

Tissue preparations for histology and immunocytochemistry. After death, the superior cornea was marked before enucleation. After a $1 \mathrm{hr}$ fixation, the anterior segments were removed except for the superior cornea, and eyes were fixed overnight at $4^{\circ} \mathrm{C}$. Then the posterior portion of each eye was divided along the vertical meridian so that each half contained the superior and inferior quadrants of either the nasal or temporal retina.

For light microscopy, eyes were fixed in $0.1 \mathrm{M}$ cacodylate buffer, $\mathrm{pH} 7.4$, containing $2 \%$ formaldehyde and $2.5 \%$ glutaraldehyde. Then the tissues were osmicated, dehydrated through a graded ethanol series, embedded in epoxy resin (Epon), and processed for evaluation. The sections $(1 \mu \mathrm{m}$ thick) were cut approximately along the horizontal meridian and passed through the optic nerve. Photoreceptor nuclei were counted in a microscopic field that spanned $100 \mu \mathrm{m}$ and was centered $300 \mu \mathrm{m}$ from the edge of the optic nerve head. This measurement was performed on both sides of the optic nerve head, and no differences were found in the number of photoreceptor nuclei between these regions. Single eyes from three individuals, taken from separate litters, were used for each age point.

For immunocytochemistry, eyes were fixed in $0.1 \mathrm{M}$ phosphate buffer, $\mathrm{pH} 7.4$, containing $4 \%$ formaldehyde. Tissues were incubated overnight with $10 \%$ sucrose in $0.1 \mathrm{M}$ phosphate buffer, $\mathrm{pH} 7.4$, and then stored in $30 \%$ sucrose phosphate buffer. The tissues were embedded in OCT (Miles Diagnostics, Elkhart, IN) and immediately snap-frozen in an isopentane-dry ice bath. Sections $\left(6 \mu \mathrm{m}\right.$ thick) were made at $-20^{\circ} \mathrm{C}$, incubated with $0.1 \%$ Triton X-100 and 10\% normal serum in PBS for 30 min at room temperature, and then washed three times with PBS for 5 min each. Then the sections were incubated overnight at $4^{\circ} \mathrm{C}$ with the primary antibody [either anti-bovine rod opsin monoclonal antibody (mAb 1D4, specific for the C terminus of rhodopsin; Hodges et al., 1988) at 1:100 dilution, anti-human blue opsin antibody at 1:3000 dilution, or anti-human red/green opsin antibody at 1:4000 dilution]. Sections were rinsed for 5 min with PBS and incubated with 1:100 biotinylated FITC secondary antibody for $30 \mathrm{~min}$ at room temperature. After three rinses with distilled water, the sections were mounted on coverslips with PermaFluor aqueous mount medium. Because the two cone types of the mouse retina are segregated spatially (Szél et al., 1992), each was counted in a $100 \mu \mathrm{m}$ microscopic field corresponding to the area of highest concentration. Specifically, anti-blue pigment-positive outer segments were counted in the inferior central region, while anti-red/green pigment-positive cells were counted in the superior central portion of the retina.

Northern blot. Mouse retinas were collected from $r d s /+$ and wild-type (C57BL/6) mice for RNA preparation. Total RNA was extracted from these tissues, using TRIzol Reagent (Life Technologies, Gaithersburg, MD), and $\sim 10 \mu \mathrm{g}$ of total RNA was separated electrophoretically on a $1 \%$ agarose gel containing $18 \%$ formaldehyde. The number of retinas used to meet this criterion ranged from two for normal mice to four for older $r d s /+$ mice. The gel was stained with ethidium bromide to check the quality of the RNA (judged by the integrity of the $28 \mathrm{~s}$ and $18 \mathrm{~s}$ rRNA bands). Then the RNA was transferred to a nitrocellulose membrane and hybridized with ${ }^{32} \mathrm{P}$-labeled bovine peripherin/rds cDNA, mouse opsin genomic DNA, or mouse blue opsin cDNA at $42^{\circ} \mathrm{C}$ in $50 \%$ formamide, $5 \times$ SSC, $1 \times$ Denhardt's, $0.5 \%$ SDS, and $0.5 \mathrm{mg} / \mathrm{ml} \mathrm{ssDNA}$. The filters were washed initially at $55^{\circ} \mathrm{C}$ in $2 \times \mathrm{SSC} / 0.5 \%$ SDS and then a second time with $0.1 \times \mathrm{SSC} / 0.5 \%$ SDS, if necessary. Then the blots were exposed to Kodak XAR film (Rochester, NY) at $-70^{\circ} \mathrm{C}$ between two intensifier screens. A densitometer scanned each individual band, and the values obtained from three different measurements were normalized with respect to the amount of actin in each corresponding lane.

Electroretinography (ERG). Mice were anesthetized with $15 \mu \mathrm{l} / \mathrm{gm}$ body weight of a saline solution containing urethane $(0.4 \mathrm{mg} / \mathrm{ml})$, ketamine $\mathrm{HCl}(1 \mathrm{mg} / \mathrm{ml})$, and xylazine $(0.4 \mathrm{mg} / \mathrm{ml})$. The pupil was dilated with $1 \%$ tropicamide and $2.5 \%$ phenylephrine $\mathrm{HCl}$, and the animals were placed on a heating pad. ERGs were recorded by using a stainless steel wire contacting the anesthetized $(1 \%$ proparacaine $\mathrm{HCl})$ corneal surface through a layer of $1 \%$ methylcellulose. A similar wire placed in the mouse served as the reference lead, and a needle electrode placed in the tail served as ground.

ERGs were recorded in two sessions. In the first, the extent of rod and cone involvement was determined by presenting strobe stimuli $(0.85 \mathrm{log}$ cd per $\mathrm{sec} / \mathrm{m}^{2}$ ) in a Nicolet ganzfeld (Madison, WI). Initially, stimuli were presented after overnight dark adaptation. At least 1 min elapsed between stimulus flashes, and responses were averaged with a Nicolet Pathfinder II signal averaging system after differential amplification (half bandpass of 1-1000 Hz). The a-wave recorded under these conditions provided a selective measure of the rod photoresponse (Goto et al., 1995, 1996; Peachey et al., 1995), whereas the b-wave included a cone-mediated contribution (Goto et al., 1995; Peachey et al., 1995). Then a steady adapting field was presented inside the ganzfeld. After at least 7 min of light adaptation, stimuli were presented at $2.1 \mathrm{~Hz}$, and 50 consecutive responses were averaged. These conditions isolated a cone-mediated ERG (Peachey et al., 1993, 1995; Goto et al., 1995).

In the second session, high-intensity stimuli were presented to the dark-adapted eye as described elsewhere (Goto et al., 1996). Stimulus flashes were generated by a photographic flash system (Novatron) and passed through an optical system to a fiber optic that was connected to the input port of an Oriel integrating sphere. Neutral density filters interposed in the optical path attenuated stimulus intensity. ERGs were recorded via the electrodes described above, which served as input to a preamplifier (WPI DAM50, Sarasota, FL; bandpass of 1-1000 Hz). The output of the preamplifier was digitized at $4000 \mathrm{~Hz}$ by a LabMaster A/D board; the board also synchronized flash presentation and data collection. Interstimulus intervals were chosen on the basis of pilot recordings with normal mice and were sufficient to maintain a stable level of dark adaptation (cf. Goto et al., 1996).

The leading edges of the a-waves obtained to these high-intensity stimuli were analyzed in terms of a modified form of the Lamb and Pugh model of rod phototransduction (Lamb and Pugh, 1992; Pugh and Lamb, 1993):

$$
P 3(i, t)=\left\{1-\exp \left[-\mathrm{iS}\left(t-t_{\mathrm{d}}\right) 2\right]\right\} \mathrm{Rm}_{\mathrm{p} 3}
$$

In Equation 1, $P 3$ represents the mass response of the rod photoreceptors and is analogous to the PIII component of Granit (1933). The amplitude of $P 3$ is expressed as a function of flash energy $(i)$ and time $(t)$ after flash onset: $S$ reflects the gain of phototransduction, $R m_{\mathrm{P} 3}$ is the maximum response, and $t_{\mathrm{d}}$ is a brief delay. This model initially was applied to data obtained from normal humans (Breton et al., 1994; Hood and Birch, 1994) and since has been used to model the leading edge of the mouse a-wave (Birch et al., 1995, 1997; Goto et al., 1996; Lyubarsky and Pugh, 1996) and responses recorded from retinitis pigmentosa (RP) patients with mutations in the peripherin/rds gene (Jacobson et al., 1996; Birch et al., 1997).

Equation 1 was fit to the leading edge of the rod ERG a-wave by a curve-fitting program that is based on a least-squares algorithm (MatLab, version 4.1; cf. Goto et al., 1996). After estimating $t_{\mathrm{d}}$, we initially fit Equation 1 to the entire data set to derive an overall value of $S$ and $R m_{\mathrm{P} 3}$. In addition, fits were made to individual responses. To accomplish this, we held values of $R m_{\mathrm{P} 3}$ and $t_{\mathrm{d}}$ constant at the values derived from the ensemble fit, and the best-fit value of $S$ was determined for each response separately.

\section{RESULTS}

\section{Expression of peripherin/rds in cone photoreceptors}

Immunocytochemical studies with anti-peripherin/rds antibodies indicate that peripherin/rds is localized along the rims of mature rod and cone disk membranes (Arikawa et al., 1992). These studies were performed on both rod-dominated (rat) and conedominated (ground squirrel) retinas (Arikawa et al., 1992). Because neither rod nor cone outer segments develop in the $r d s / r d s$ 


\section{$\begin{array}{ll}\text { A. Peripherin/rds } & \text { B. Rhodopsin }\end{array}$}

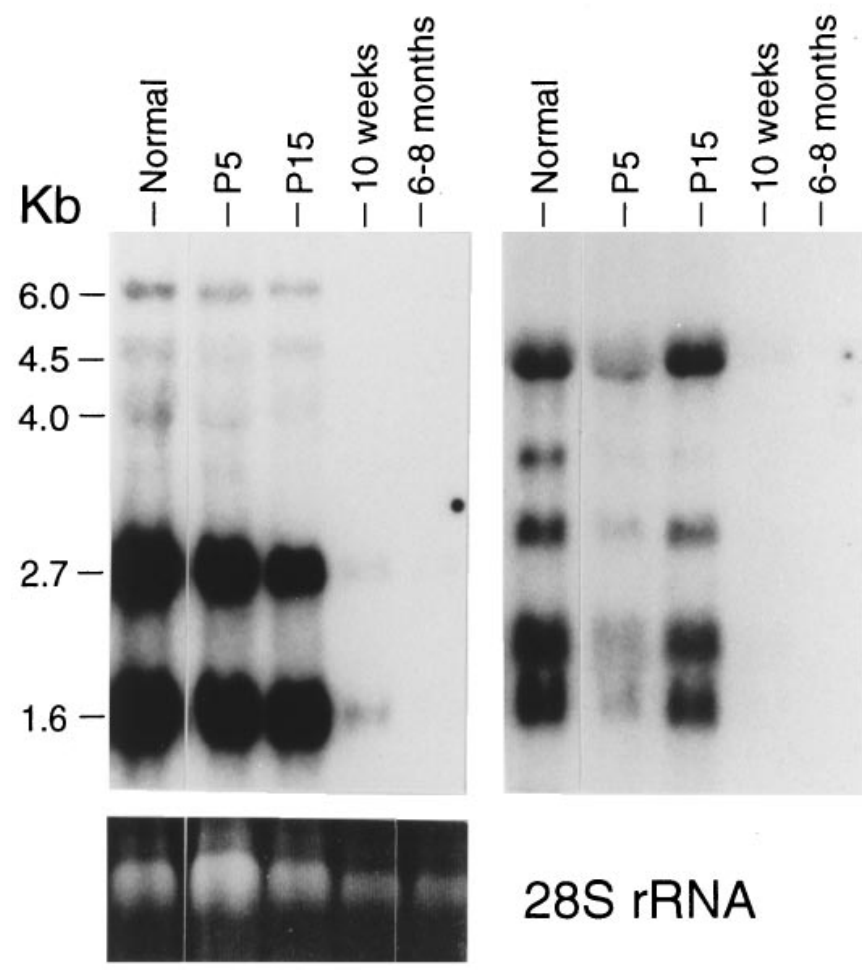

Figure 1. Northern blot analysis of $r d / r d$ mice at the ages indicated. $A$, Blot probed for peripherin/rds transcripts. Note that a small signal is retained at P70, when all rods were lost and some cones are present. At 6-8 months of age, no peripherin/rds transcripts were detected because of the complete loss of both rods and cones. $B$, Blot probed for rod opsin transcripts. Note that the signal for the opsin transcripts decreases rapidly with age and is not discernible at P70 and older.

retina, it is likely that the same mutant peripherin/rds gene is expressed in rod and cone cells. To examine this issue, we evaluated peripherin/rds expression in $r d / r d$ mice at ages representative of the degenerative process (Fig. 1). In the $r d / r d$ retina it is well established that a rapid degeneration occurs in all retinal regions, which precedes a much slower cone degeneration (Carter-Dawson et al., 1978). At early ages [postnatal day (P) 5, P15], when the rod degeneration is severe but incomplete (Carter-Dawson et al., 1978), the expression of both peripherin/rds (Fig. 1A) and $\operatorname{rod}$ opsin (Fig. $1 B$ ) can be detected. At 10 weeks of age, when the rod degeneration is complete (Carter-Dawson et al., 1978), rod opsin expression cannot be discerned above the background level (Fig. $1 B)$. At the same age it was possible to detect a low level of expression of peripherin/rds in $r d / r d$ mice (Fig. 1A). A longer exposure of the same blot showed a slightly stronger peripherin/rds signal, but still no signal from the rhodopsin gene (data not shown). Because the $r d$ defect is rod-specific (Bowes et al., 1990; Pittler and Baehr, 1991) and leads to a rapid degeneration of the rod photoreceptors (Carter-Dawson et al., 1978), the residual peripherin/rds signal must reflect the small population of cone photoreceptors that survive the early cascade of rod photoreceptor degeneration (Carter-Dawson et al., 1978; Foster et al., 1991). Messages for opsin and peripherin/rds were absent in retinas from older $r d / r d$ mice (Fig. 1, 6-8 months) despite the fact that a small number of cone nuclei are still present at this age (Carter-Dawson et al.,
1978). Overall, these results indicate that the same $r d s$ mutation is expressed in both rod and cone photoreceptor cells, a conclusion that agrees with previous work that used a different approach (Arikawa et al., 1992).

\section{Photoreceptor cell loss in rds/+ retinas}

Figure 2 shows representative cross sections taken from a 2month-old normal mouse $(A)$ and from $r d s /+$ mice at $1(B), 2$ $(C)$, and $3(D)$ months of age. At 1 month, $r d s /+$ mice appear to retain a near-normal number of photoreceptor cells in the ONL. Examination of the ONL at later ages shows a distinct reduction in the $r d s /+$ retina and only a modest decline in retinas obtained from normal littermates (Fig. 2C,D). These observations, which agree overall with previous reports (Hawkins et al., 1985; Nir et al., 1990), are quantified in Figure $2 E$, which plots the average $( \pm$ $1 \mathrm{SD})$ number of cells counted within a $100 \mu \mathrm{m}$ span of the central retina. At each age the number of cells in the ONL was decreased significantly from normal (all $p<0.05$ ). A prominent feature of the $r d s /+$ retina is the disorganized and abnormally shorter outer segments (Fig. 2B-D; Hawkins et al., 1985). As shown in Figure $2 F$, the length of the outer segments was reduced significantly at 1 month but did not change appreciably in mice as old as 3 months. The inner retinal layers as well as the retinal pigment epithelium retained a normal appearance throughout the age range examined (Fig. 2).

\section{Opsin immunoreactivity during the degeneration of the rds/+ retina}

To examine further the $r d s /+$ rod outer segment and the distribution of opsin, we performed immunocytochemistry with 1D4, a monoclonal antibody that identifies rod opsin (Hodges et al., 1988). Figure $3, A-C$, presents retinal sections obtained from a 1 -month-old normal mouse $(A, D)$, a 1 -month-old $r d s /+$ mouse $(B, E)$, and a 3-month-old $r d s /+$ mouse $(C, F)$. In each case the top panel shows the result of exposure to $1 \mathrm{D} 4$, whereas the bottom panel is a Nomarski image of the same retinal field. Like the normal retina, $r d s /+$ retinas at all ages studied showed that the majority of the labeling was restricted to the outer segments. This pattern, which is similar to that reported by Cantera et al. (1990), indicates that the $r d s$ mutation does not interfere with the synthesis and localization of opsin to the outer segment. Furthermore, no immunoreactivity was seen in the synaptic terminal of the photoreceptor cells. Thus, although the degeneration reduces the overall length of the rod outer segment, the normal pattern of localization for rod opsin is retained.

\section{Cone photoreceptor cell loss in rds/+ retina}

The effect of the rds mutation on cone photoreceptor cells has received little attention. This may reflect the fact that the mouse retina is rod-dominated with only a small $(\sim 3 \%)$ proportion of cones (Carter-Dawson and LaVail, 1979). However, it is known that the mouse retina contains at least two cone types (Jacobs et al., 1991; Szél et al., 1992; Chiu and Nathans, 1994) with a large scale topographical separation in their distribution (CarterDawson and LaVail, 1979; Szél et al., 1992; Chiu and Nathans, 1994). The red/green cones are found at the highest concentration in the superior retina, whereas the highest concentration of blue cones occurs in the inferior retina (Szél et al., 1992); between the superior and inferior zones lies a transitional band wherein a single cone may express both red/green and blue pigments (Röhlich et al., 1994).

To determine the effect of the $r d s$ mutation on the blue and red/green cone cells, we used monoclonal antibodies specific to 

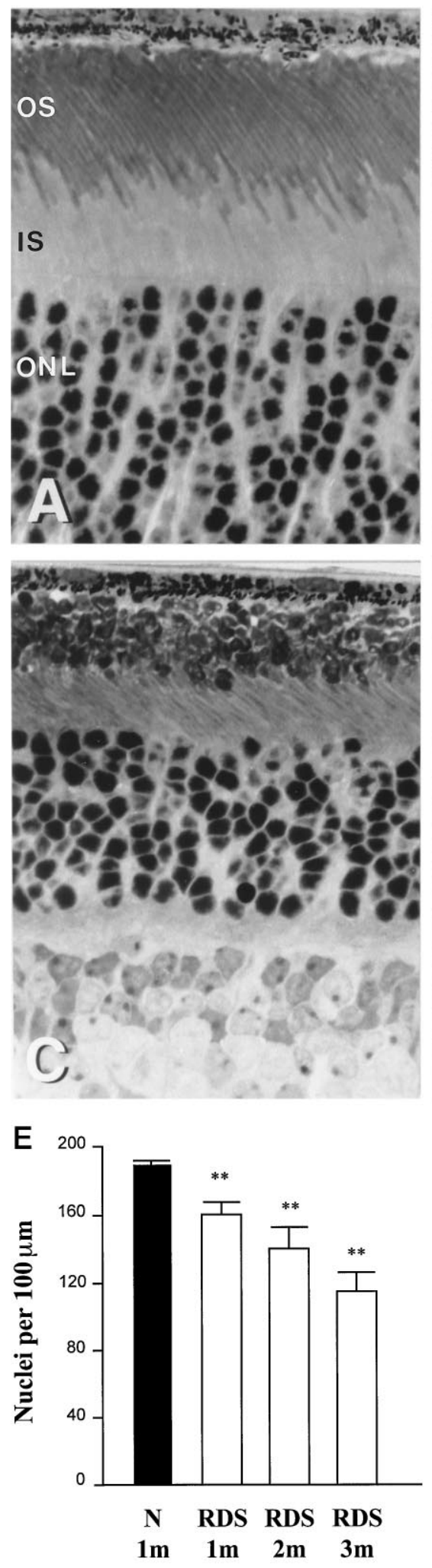
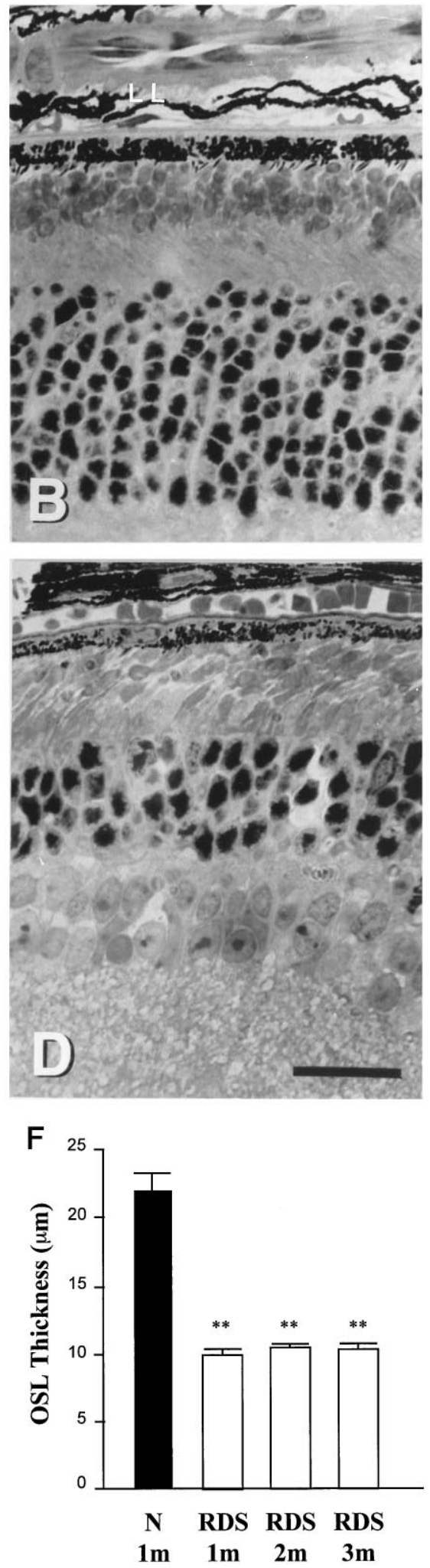

Figure 2. Light micrographs showing changes in the central parts of the retina of normal and $r d s /+$ mice. $A$, Retinal cross section taken from a 2-month-old normal mouse. $B-D$, Retinal cross sections taken from 1-, 2-, and 3-month-old $r d s /+$ mice. $O S$, Outer segments; $I S$, inner segments; $O N L$, outer nuclear layer. Scale bar, 20 $\mu \mathrm{m}$. $E$, Counts of total photoreceptor nuclei. $F$, Thickness of outer segment layer. Each error bar represents the mean $\pm 1 \mathrm{SD}$ for at least three measurements. either the blue or red/green pigment. Figure $4 A-C$ presents retinal sections obtained from the inferior central region of a 1-month-old normal mouse $(A, D)$, a 1-month-old $r d s /+$ mouse $(B, E)$, and a 3-month-old $r d s /+$ mouse $(C, F)$. In each case the top panel shows the result of exposure to an antibody against blue cone opsin, whereas the bottom panel is a Nomarski image of the same section. In the top panels immunoreactivity is confined to the blue cone outer segment. Overall, the pattern of blue cone immunocytochemical staining observed in our normal and $r d s /+$ data was similar to that reported previously (Szél et al., 1992; Chiu and Nathans, 1994). With increasing age, however, the number of blue cones present in the $r d s /+$ retina appears to decline. These data are quantified in Figure $4 G$ for blue cones and in Figure $4 H$ for red/green cones. The red/green cones were 

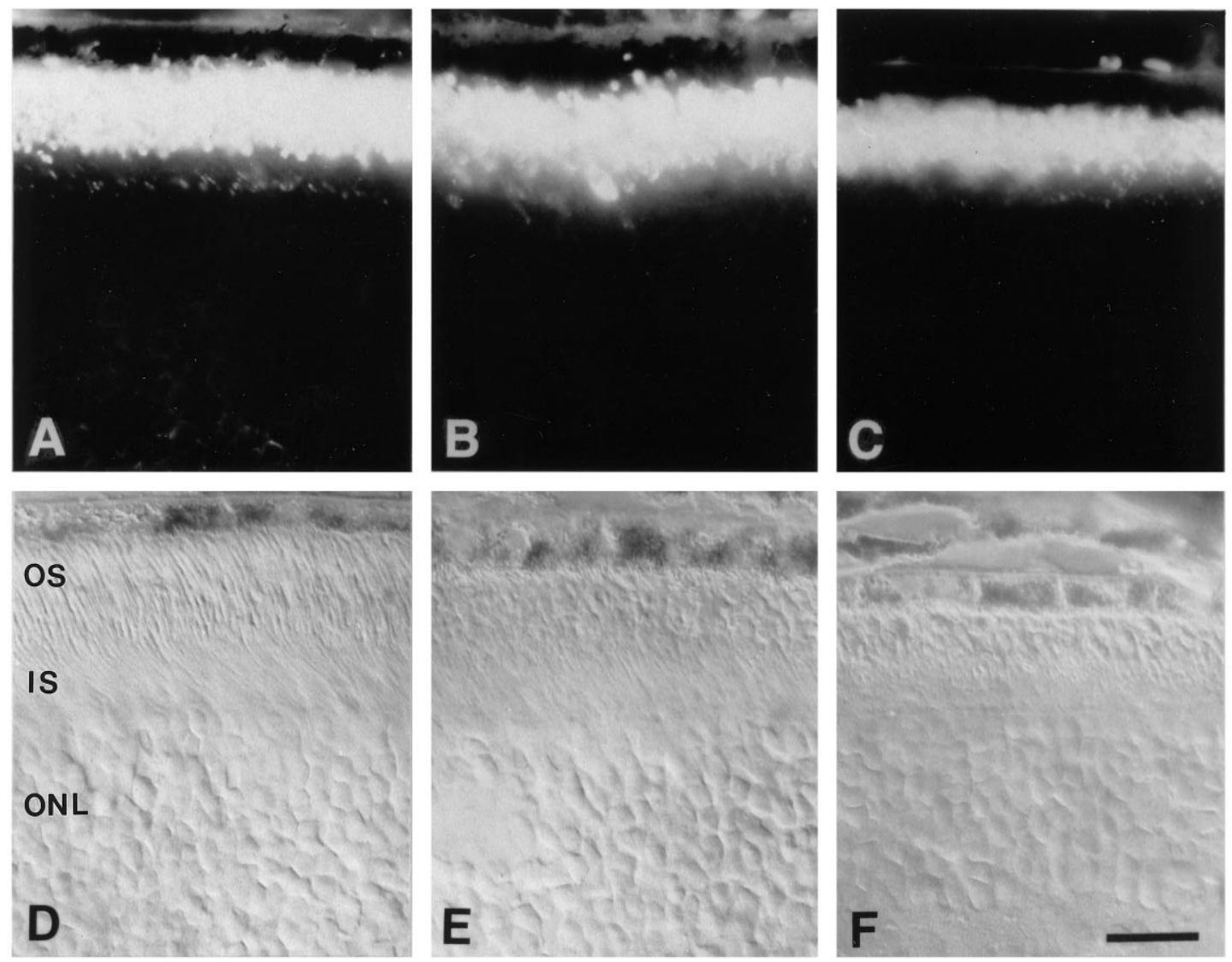

Figure 3. Cryostat sections of retina from normal and $r d s /+$ mice stained for rod opsin (1D4). Shown are retinal cross sections from a normal 2-month-old mouse $(A)$ and $r d s /+$ mice at 1 month $(B)$ and 3 months $(C) . D-F$, Nomarski images of retinal sections shown in $A-C$, respectively. $O S$, Outer segments; $I S$, inner segments; $O N L$, outer nuclear layer. Scale bar, $20 \mu \mathrm{m}$.

measured in the central superior region of the retina. For both cone types there is an age-related decline in labeled cells in $r d s /+$ mice. However, the reduction was more modest for blue cones.

Figure 5 compares the relative degrees of rod and cone degeneration in $r d s /+$ mice aged $1-3$ months. Plotted are the relative numbers of blue or red/green cones (data of Fig. $4 G, H$ ) as a function of the relative number of rods. To derive the rod counts, we adjusted the total number of photoreceptors (see Fig. $2 E$ ) by the corresponding cone counts (Fig. 4G,H). The diagonal line represents an equivalent reduction in the two photoreceptor populations. The area above the line indicates a relative preservation of cones, whereas the area below the line indicates that cones are affected more severely than rods. It is apparent that the $r d s /+$ mouse data fall above the diagonal, indicating a relative preservation of cone photoreceptors.

\section{Rod and cone electroretinography in rds/+ mice}

Figure $6 A$ presents ERGs recorded under dark- and light-adapted conditions from a 2-month-old normal mouse (top traces) and $r d s /+$ mice at the ages indicated. Dark-adapted (rod-dominated) responses are reduced in amplitude at all ages, and there is an age-related decline. In comparison, the light-adapted cone ERG of 2-month-old $r d s /+$ mice appears normal in amplitude; at later ages this response declines moderately. These data indicate that the $r d s$ defect compromises rod more than cone function. Figure $6 B$ analyzes this issue quantitatively by plotting rod- and conemediated ERG components against each other. Here, data are expressed relative to the respective normal mean, and each data point represents an individual $r d s /+$ mouse. The solid diagonal line again illustrates the relationship expected if rod and cone responses are affected equally. All of the data fall above the line, consistent with the impression that cone function is relatively spared in $r d s /+$ mice.

The observed reduction in the rod ERG a-wave could reflect a number of outer segment abnormalities. The histology data indicate that the dark current underlying the a-wave is decreased in $r d s /+$ mice by at least two factors: a decrease in the length of the outer segment (see Fig. $2 F$ ) and a decline in the number of viable photoreceptors (see Fig. $2 E$ ). To determine whether these are the only factors, we used high-intensity stimuli to allow the application of Equation 1 to the leading edge of the a-wave. Figure $6 C$ presents the leading edge of a-waves recorded from a 2-month-old $r d s /+$ mouse. The dashed line represents the fit of the model to the series of responses recorded here and describes the data well.

Figure $6 D$ presents the values of $S$ derived when Equation 1 was fit to each individual response. Across the stimulus range used here, the values obtained from $r d s /+$ mice were not different from those obtained from normal mice. This indicates that the amplification characteristics of the phototransduction cascade are operating with normal efficiency, despite the overall disorganization and shortening of the outer segment. As a result, the a-wave reductions reflect primarily the short rod outer segments present in $r d s /+$ mice and the age-related decline in the total number of viable rod photoreceptors. A similar conclusion recently has been presented by Birch et al. (1997). 

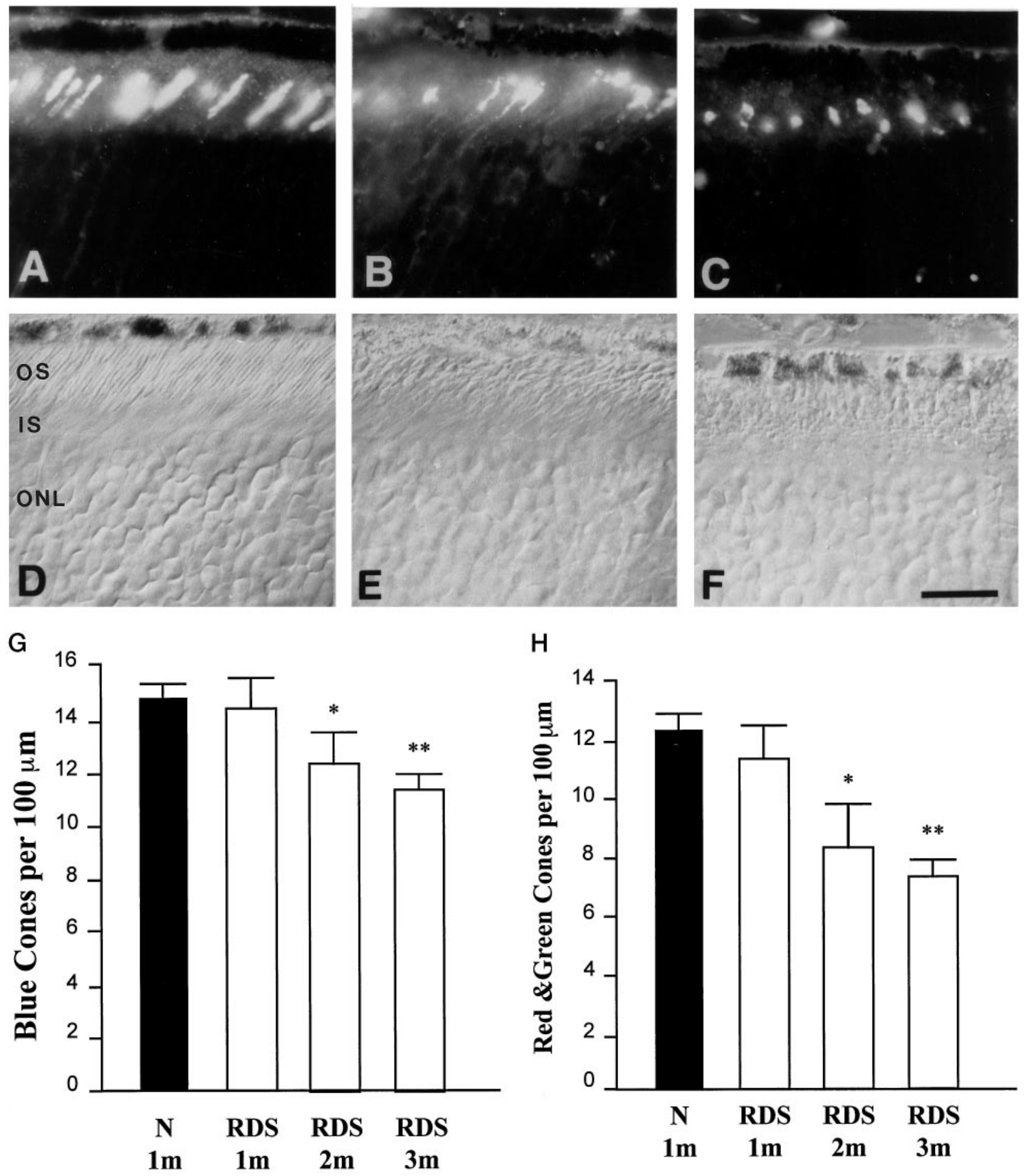

Figure 4. Cryostat sections of retina from normal and $r d s /+$ mice stained for cone opsins. Shown are retinal cross sections immunostained for blue cone opsin from a normal 2-month-old mouse $(A)$ and $r d s /+$ mice at 1 month $(B)$ and 3 months $(C) . D-F$, Nomarski images of retinal sections shown in $A-C$, respectively. $O S$, Outer segments; $I S$, inner segments; $O N L$, outer nuclear layer. Scale bar, $20 \mu \mathrm{m}$. $G$, Counts of blue cone immunoreactive cells measured in the inferior central region of the retina. $H$, Counts of red/green cone immunoreactive cells measured in the superior central region of the retina. Each error bar represents the mean \pm 1 SD for at least three measurements.

\section{Expression levels of peripherin/rds, opsin, and blue pigment mRNA in rds/+ retinas}

We have examined the levels of expression of three photoreceptorspecific genes (peripherin/rds, rhodopsin, and blue opsin) in the retinas of $r d s /+$ mice before and after the onset of photoreceptor cell death. Figure 7 shows the RNA blot analysis obtained by using cDNA for mouse peripherin/rds (Cheng et al., 1997), genomic DNA for mouse rod opsin (Al-Ubaidi et al., 1990), and cDNA for mouse blue cone opsin (Naash et al., 1992) to hybridize total RNA extracted from normal and $r d s /+$ retinas at 1,2 , or 3 months of age. 


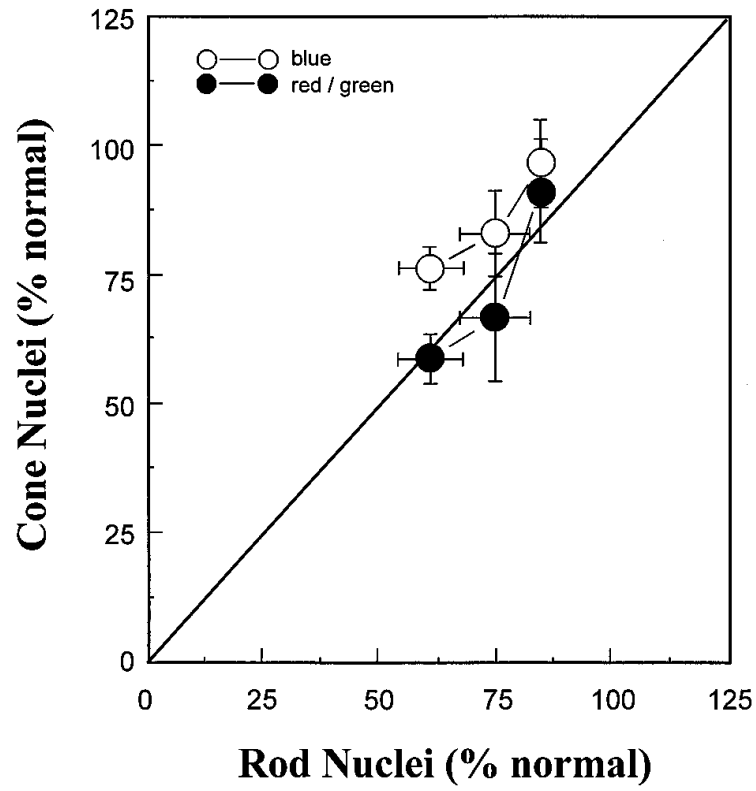

Figure 5. Relative retention of rod and cone photoreceptors in $r d s /+$ mice. Each axis is expressed as a percentage of normal. The two cone subtypes are represented by different symbols (open circles, blue; filled circles, red/green). The solid diagonal line represents an equivalent change from normal. The area above the line indicates a relative preservation of cones; the area below the line indicates a relative preservation of rods.

The top portion of each panel illustrates a representative Northern blot from one experiment. The bottom graph presents average $( \pm 1 \mathrm{SD})$ results obtained from densitometry of blots derived from three different RNA preparations. When probed for peripherin/rds (Fig. $7 A$ ), normal mice generate two major (1.6 and $2.7 \mathrm{~kb})$ and three minor (4.0, 5.5, and $6.5 \mathrm{~kb})$ transcripts that probably represent the different poly $\left(\mathrm{A}^{+}\right)$signals that are used in the synthesis of this protein (cf. Ma et al., 1995; Cheng et al., 1997). These bands also are seen in RNA isolated from $r d s /+$ mice (Fig. $7 A$ ). In addition, heterozygotes generate two additional high-molecular-weight transcripts; these correspond to the insertion of the $9.2 \mathrm{~kb}$ repetitive element that underlies the $r d s$ defect (Travis et al., 1989; Ma et al., 1995). If we consider only the normal transcripts, at 1 month of age, peripherin/rds levels in the $r d s /+$ retina are approximately one-half $(45.8 \%)$ of normal. This agrees with the histological analysis that there is only a slight decline in the number of photoreceptors at this age. As a result, the measured decrease in peripherin/rds reflects the fact that $r d s /+$ mice express only one functional allele. At 2 and 3 months of age, peripherin/rds levels remain stable in the normal retinas but decline in $r d s /+$ retinas at a rate that parallels the loss of cells observed histologically (see Fig. 2).

As shown in Figure $7 B$, normal and $r d s /+$ mice have similar expression levels of the rod opsin gene at 1 month of age. This observation is in agreement with the histological evidence for a near-normal number of ONL cells at this age (see Fig. 2E) and the immunocytochemical evidence (see Fig. 5) that rod opsin is localized to the rod outer segment of $r d s /+$ mice; it also indicates that transcription of the rod opsin gene operates normally. At later ages an $\sim 50 \%$ decline in transcripts for rod opsin was observed. This decrease cannot be attributed only to a loss of rod photoreceptors, because a more modest decrease actually is observed (see Fig. 2E). Instead, this decline must reflect a decreased rate in mRNA synthesis. A similar phenomenon occurs for the blue cone opsin transcripts (Fig. 7), although the extent of decline at 2 and 3 months of age is less marked than for rod opsin. When expressed as normalized values, the decline in the expression of blue cone opsin is more gradual than that for rod opsin (Fig. 7).

\section{DISCUSSION}

The present study has evaluated the effect of peripherin/rds haploinsufficiency on rod and cone photoreceptors. When we initiated this study, it was important to confirm that the same gene was expressed in both rods and cones. As shown in Figure 1, peripherin/rds transcripts persist in retinas devoid of rod photoreceptors and rhodopsin message. Because the peripherin/rds signal detected in Figure 1 was obtained by using high-stringency hybridization, this signal must reflect the same gene being expressed in all photoreceptors.

Compared with corresponding measures for cones, rods developed a more severe degeneration as measured by the number of surviving photoreceptors, the retention of ERG amplitude, and the maintenance of mRNA levels. A possible explanation for this difference is that the remaining peripherin/rds allele is upregulated in cone photoreceptors to a level that maintains functional integrity. However, this does not seem to be the case, because we did not see any increase in the mRNA level of the normal peripherin/rds allele at 1 month of age. Alternatively, it is possible that the delayed time course of cone involvement reflects a relative tolerance of cone photoreceptors to the $r d s$ gene defect. Cone and rod outer segments differ in several important respects (Eckmiller, 1997). Although the cone outer segment appears as a folded system of membranes, rod outer segments are composed of a rigid stack of individual disks. Moreover, the rod outer segment is much longer than the cone outer segment and contains a greater number of disks. Therefore, it is possible that the product of both peripherin/rds alleles is required to construct the more rigid and extensive rod outer segment. The cone outer segment also possesses several structural features, including distal invaginations and a relatively more extensive ciliary axoneme, that differ from rods (Eckmiller, 1997) and may contribute to overall cone outer segment integrity. In this view, cone degeneration arises primarily as a secondary effect of rod degeneration. In fact, secondary cone degeneration has been observed in a number of naturally occurring and genetically engineered mouse lines in which the expression of the gene defect is controlled by a rodspecific promoter (Carter-Dawson et al., 1978; Johnson et al., 1989; Goto et al., 1995; McCall et al., 1996). At present, it is not possible to distinguish whether one or both of these factors contribute to the relative preservation of cones. However, this question could be resolved by examining cone structure and function in $r d s /+$ mice "rescued" by the expression of a normal copy of peripherin/rds in rod photoreceptors (Travis et al., 1992).

Total cell counts indicated that the $r d s /+$ defect is more detrimental to red/green cones than to blue cones. This observation could reflect an increased susceptibility of red/green cones to the defect in maintaining the structure of the outer segment. Alternatively, this result could reflect regional differences in disease severity; as reviewed above, the two cone subtypes are effectively segregated to the inferior or superior retinas, with little overlap (Szél et al., 1992). In VPP transgenic mice a more severe degeneration is observed in the inferior retina under typical cyclic light conditions (Naash et al., 1996a); this regional difference disappears with mice reared in darkness. In another transgenic line expressing the G90D rhodopsin mutation, the superior retina is 
A

Dark-Adapted

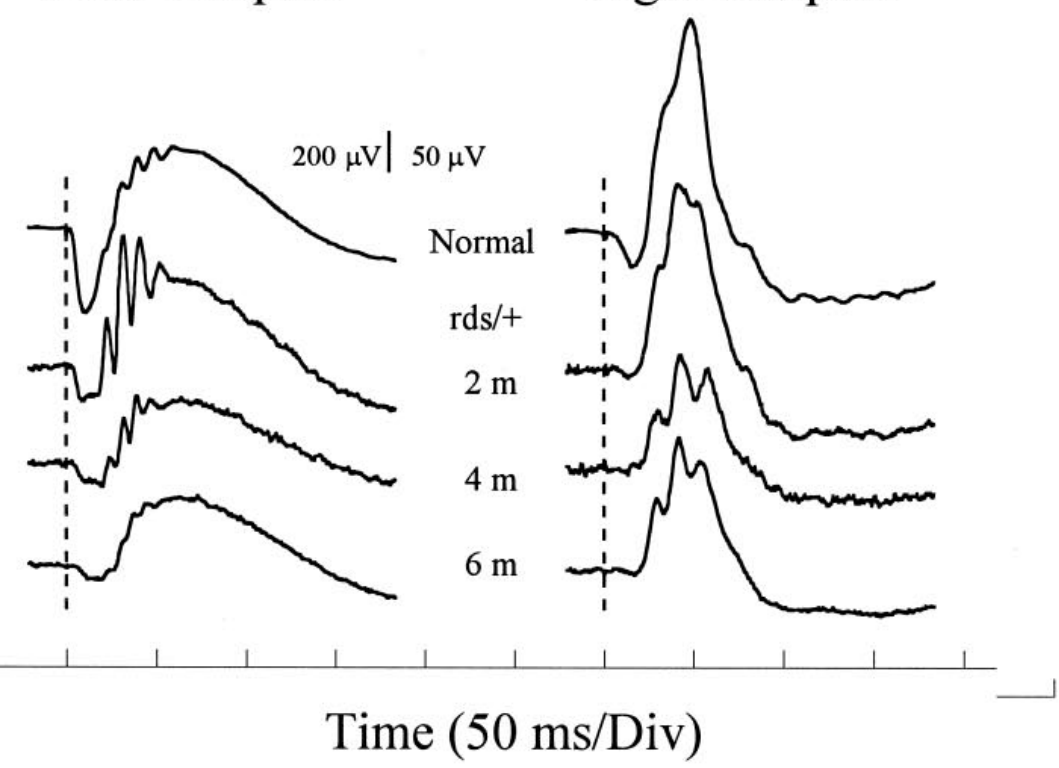

B

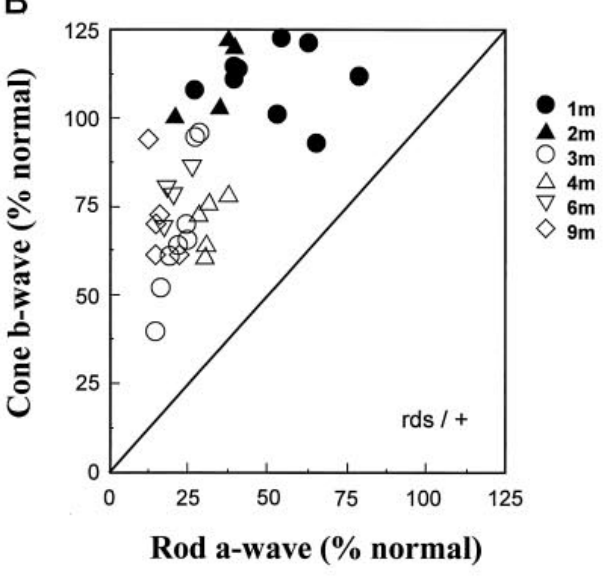

D

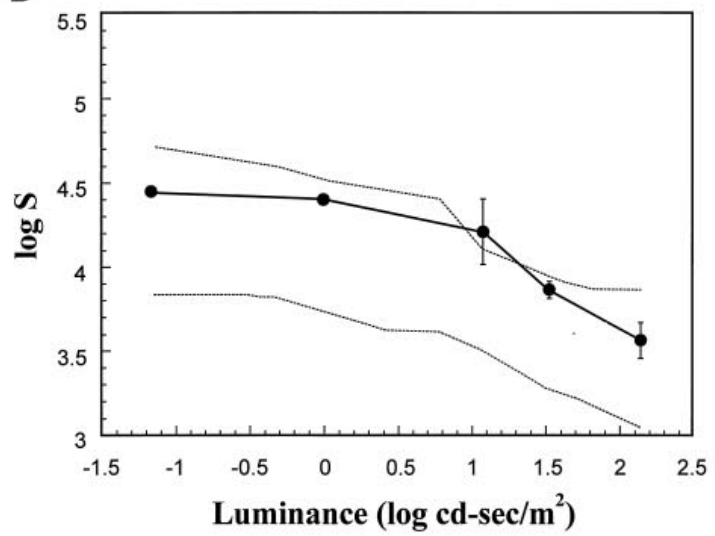

C

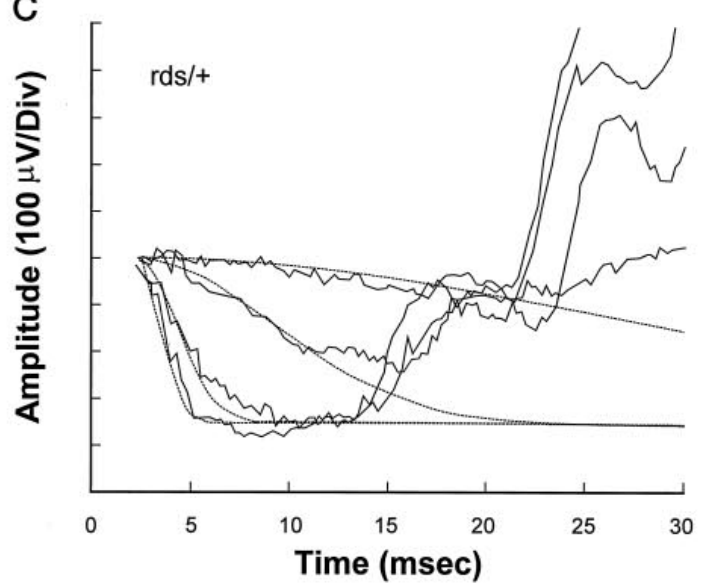

Figure 6. Electroretinography. A, Representative ERGs obtained from a normal mouse (top trace) and from $r d s /+$ heterozygotes at the ages indicated. Responses are to a high-intensity strobe flash $\left(0.85 \log \mathrm{cd} \mathrm{sec} / \mathrm{m}^{2}\right)$ presented to the dark-adapted eye (left) or superimposed on a $1.3 \mathrm{log} \mathrm{cd} / \mathrm{m}^{2}$ adapting field (right). B, Amplitude of cone ERG b-wave plotted as a function of rod ERG a-wave. Data are expressed relative to the normal mean. Each symbol represents an individual mouse. The solid diagonal line represents an equivalent decrease in the two response measures; points falling above this line indicate a relative sparing of cone responses; a relative sparing of rod responses would result in points falling below the line. C, Rod ERG a-waves obtained from a 1-month-old $r d s /+$ mouse in response to high-intensity flash stimuli. The solid lines represent the response actually recorded, whereas $d a s h e d$ lines represent the least-squares fit of Equation 1. D, Value of amplification parameter $S$ plotted as a function of stimulus intensity. Dashed lines indicate the range of normal, whereas the data points indicate the average ( $\pm 1 \mathrm{SD}$ ) value obtained from four $r d s /+$ mice. 
A Peripherin/rds Rhodopsin
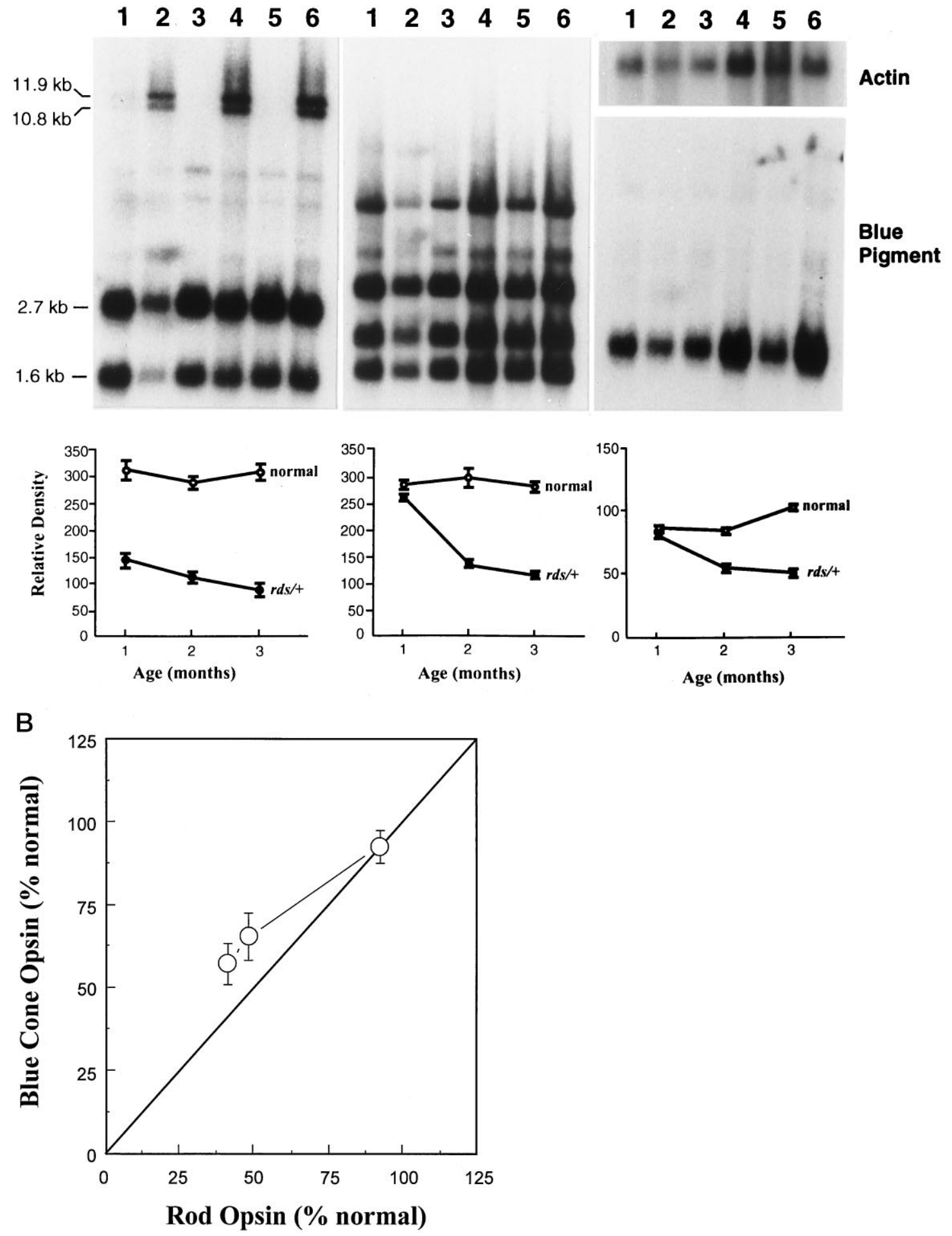

Figure 7. Northern blot analysis. A, Top panels show representative blots for peripherin/rds, rod opsin, and blue cone opsin, along with an actin control. Bottom panels show the corresponding average ( $\pm 1 \mathrm{SD}$ ) levels obtained for three different blots. For peripherin/rds, note the additional high-molecularweight transcripts in the $r d s /+$ lanes; only the normal-sized transcripts were measured. $B$, Comparison of blue cone opsin signal plotted as a function of the corresponding rod opsin signal at each age analyzed. Data are expressed relative to normal. Each point represents the average $( \pm 2$ SD) value obtained from three assays, each using retinas obtained from four $r d s /+$ mice at 1,2, and 3 months of age. The solid diagonal line represents an equivalent decrease in the two measures; points falling above this line indicate a relative sparing of cone transcripts. 
affected more severely, regardless of whether animals were reared in darkness or under cyclic light (Naash et al., 1996b). It is possible that the vulnerability of the mouse cone population also varies from region to region, with the net effect reported here.

The ERG results reported here were obtained under conditions used to examine human patients with peripherin/rds gene defects. As a result, two lines of comparison can be drawn between $r d s /+$ mice and patients heterozygous for peripherin/rds gene mutations. At the level of the rod a-wave, patients with either insertion or deletion mutations in peripherin/rds have an overall reduction in a-wave amplitude but retain normal gain (Jacobson et al., 1996; Birch et al., 1997). This pattern of results also was found to apply to $r d s /+$ mice (Fig. 4; Birch et al., 1997) and suggests that the mechanism underlying the defect may be similar. However, this pattern also is associated with rhodopsin gene defects in human patients (Hood and Birch, 1993; Jacobson et al., 1994; Shady et al., 1995) and the expression of a mutant rhodopsin gene in transgenic mice (Goto et al., 1996). At present, the retention of normal amplification $(S)$ in the face of an overall amplitude reduction does not distinguish RP pedigrees from one another, although the reverse can be seen in other situations (Johnson and Hood, 1996).

The cone ERG results seem to distinguish the $r d s /+$ mouse model from many human conditions involving peripherin/rds gene defects. Dominant peripherin/rds mutations typically are accompanied by significant cone abnormalities, even in relatively young patients (Kajiwara et al., 1991, 1993; Wells et al., 1993; Fishman et al., 1994; Kemp et al., 1994; Nakazawa et al., 1994; Wroblewski et al., 1994; Gorin et al., 1995; Jacobson et al., 1996). In comparison, $r d s /+$ mice exhibit a relative sparing of the cone ERG throughout the age range tested. However, Kajiwara et al. (1993) reported two patients from a pedigree carrying a null mutation in the peripherin/rds gene, resulting in a premature stop codon at position 43. Although the older patient had severe retinal degeneration, the younger patient exhibited a selective reduction in the rod-mediated ERG; cone-mediated potentials were normal. This pattern of results resembles that observed in young $r d s /+$ mice and may indicate that a similar process is involved in both situations.

In sum, our results indicate the importance of evaluating the effect of a genetic defect on rod and cone photoreceptor characteristics. Although rods are more numerous in most mammalian retinas, cones mediate many specialized visual functions. Therefore, in evaluating the status of the retina, we can obtain a complete picture only by a comprehensive analysis of all affected cell types.

\section{REFERENCES}

Al-Ubaidi MR, Pittler SJ, Champagne MS, Triantafyllos JT, McGinnis JF, Baehr W (1990) Mouse opsin: gene structure and molecular basis of multiple transcripts. J Biol Chem 265:20563-20569.

Arikawa K, Molday LL, Molday RS, Williams DS (1992) Localization of peripherin/rds in the disk membranes of cone and rod photoreceptors: relationship to disk membrane morphogenesis and retinal degeneration. J Cell Biol 116:659-667.

Birch DG, Kedzierski W, Nusinowitz S, Anderson JL, Travis GH (1995) Rod photoreceptor function in transgenic mice expressing mutant rds/peripherin. ARVO abstracts. Invest Ophthalmol Vis Sci 35:S641.

Birch DG, Travis GH, Locke KG, Hood DC (1997) Rod ERGs in mice and humans with putative null mutations in the RDS gene. In: Vision science and its applications, Vol 1, 1997 OSA technical digest series, pp 262-265. Washington, DC: Optical Society of America.

Bowes C, Li T, Danciger M, Baxter LC, Applebury ML, Farber DB (1990) Retinal degeneration in $r d$ mouse is caused by a defect in the $\beta$ subunit of rod cGMP-phosphodiesterase. Nature 347:677-680.
Breton ME, Schueller AW, Lamb TD, Pugh Jr EN (1994) Analysis of ERG a-wave amplification and kinetics in terms of the G-protein cascade of phototransduction. Invest Ophthalmol Vis Sci 35:295-309.

Cantera R, von Schantz M, Chader GJ, Ehinger B, Sanyal S, van Veen T (1990) Postnatal development of photoreceptor-specific proteins in mice with hereditary retinal degeneration. Exp Biol 48:305-312.

Carter-Dawson LD, LaVail MM (1979) Rods and cones in the mouse retina. I. Structural analysis using light and electron microscopy. J Comp Neurol 188:245-262.

Carter-Dawson LD, LaVail MM, Sidman RL (1978) Differential effect of the $r d$ mutation on rods and cones in the mouse retina. Invest Ophthalmol Vis Sci 17:489-498.

Cheng T, Al-Ubaidi MR, Naash MI (1997) Structural and developmental analysis of the mouse peripherin/rds gene. Somat Cell Mol Genet 23:165-183.

Chiu MI, Nathans J (1994) A sequence upstream of the mouse blue visual pigment gene directs blue cone-specific transgene expression in mouse retinas. Vis Neurosci 11:773-780.

Eckmiller MS (1997) Morphogenesis and renewal of cone outer segments. Prog Ret Eye Res 16:401-441.

Farrar GJ, Kenna P, Jordan SA, Kumar-Singh R, Humphries MM, Sharp EM, Sheils DM, Humphries P (1991) A three-base-pair deletion in the peripherin-RDS gene in one form of retinitis pigmentosa. Nature 354:478-480.

Fishman GA, Stone E, Gilbert LD, Vandenburgh K, Sheffield VC, Heckenlively JR (1994) Clinical features of a previously undescribed codon 216 (proline to serine) mutation in the peripherin/retinal degeneration slow gene in autosomal dominant retinitis pigmentosa. Ophthalmology 101:1409-1421.

Foster RG, Provencio I, Hudson D, Fiske S, DeGrip W, Menaker M (1991) Circadian photoreception in the retinally degenerate mouse $(r d / r d)$. J Comp Physiol [A] 169:39-50.

Gorin MB, Jackson KE, Ferrell RE, Sheffield VC, Jacobson SG, Gass JDM, Mitchell E, Stone EM (1995) A peripherin/retinal degeneration slow mutation (Pro-210-Arg) associated with macular and peripheral retinal degeneration. Ophthalmology 102:246-255.

Goto Y, Peachey NS, Ripps H, Naash MI (1995) Functional abnormalities in transgenic mice expressing a mutant rhodopsin gene. Invest Ophthalmol Vis Sci 36:62-71.

Goto Y, Peachey NS, Ziroli NE, Seiple WH, Gryczan C, Pepperberg DR, Naash MI (1996) Rod phototransduction in transgenic mice expressing a mutant opsin gene. J Opt Soc Am A 13:577-585.

Granit R (1933) The components of the retinal action potential in mammals and their relation to the discharge of the optic nerve. J Physiol (Lond) 77:207-239.

Hawkins RK, Jansen HG, Sanyal S (1985) Development and degeneration of retina in $r d s$ mutant mice: photoreceptor abnormalities in the heterozygotes. Exp Eye Res 41:701-720.

Hodges RS, Heaton RJ, Parker JM, Molday L, Molday RS (1988) Antigen-antibody interaction. Synthetic peptides define linear antigenic determinants recognized by monoclonal antibodies directed to the cytoplasmic carboxyl terminus of rhodopsin. J Biol Chem 263:11768-11775.

Hood DC, Birch DG (1994) Rod phototransduction in retinitis pigmentosa: estimation and interpretation of parameters derived from the rod a-wave. Invest Ophthalmol Vis Sci 35:2948-2961.

Jacobs GH, Neitz J, Deegan II JF (1991) Retinal receptors in rodents maximally sensitive to ultraviolet light. Nature 353:655-656.

Jacobson SG, Kemp CM, Cideciyan AV, Macke JP, Sung C, Nathans J (1994) Phenotypes of stop codon and splice site rhodopsin mutations causing retinitis pigmentosa. Invest Ophthalmol Vis Sci 35:2521-2534.

Jacobson SG, Cideciyan AV, Kemp CM, Sheffield VC, Stone EM (1996) Photoreceptor function in heterozygotes with insertion or deletion mutations in the RDS gene. Invest Ophthalmol Vis Sci 37:1662-1674.

Johnson LV, Blanks JC, Hageman GS (1989) Effects of retinal degenerations on the cone matrix sheath. In: Inherited and environmentally induced retinal degeneration (LaVail MM, Anderson EA, Hollyfield JG, eds), pp 217-232. New York: Liss.

Johnson MA, Hood DC (1996) Rod photoreceptor transduction is affected in central retinal vein occlusion associated with iris neovascularization. J Opt Soc Amer A 13:572-576.

Kajiwara K, Hahn LB, Mukai S, Travis GH, Berson EL, Dryja TP (1991) Mutations in the human retinal degeneration slow gene in autosomal dominant retinitis pigmentosa. Nature 354:480-483.

Kajiwara K, Sandberg MA, Berson EL, Dryja TP (1993) A null muta- 
tion in the human peripherin/rds gene in a family with autosomal dominant retinitis punctata albescens. Nat Genet 3:208-212.

Kemp CM, Jacobson SG, Cideciyan AV, Kimura AE, Sheffield VC, Stone EM (1994) RDS gene mutations causing retinitis pigmentosa or macular degeneration lead to the same abnormality in photoreceptor function. Invest Ophthalmol Vis Sci 35:3154-3162.

Lamb TD, Pugh Jr EN (1992) A quantitative account of the activation steps involved in phototransduction in amphibian photoreceptors. J Physiol (Lond) 499:719-758.

Lyubarsky AL, Pugh Jr EN (1996) Recovery phase of the murine rod photoresponse reconstructed from electroretinographic recordings. J Neurosci 16:563-571.

Ma J, Norton JC, Allen AC, Burns JB, Hasel KW, Burns JL, Sutcliffe JG, Travis GH (1995) Retinal degeneration slow $(r d s)$ in mouse results from simple insertion of a $t$ haplotype-specific element into protein-coding exon II. Genomics 28:212-219.

McCall MA, Gregg RG, Merriman K, Goto Y, Peachey NS, Stanford LR (1996) Morphological and physiological consequences of the selective elimination of rod photoreceptors in transgenic mice. Exp Eye Res 63:35-49.

Molday RS (1994) Peripherin/rds and rom-1: molecular properties and role in photoreceptor degeneration. Prog Ret Eye Res 13:271-299.

Naash MI, Al-Ubaidi MR, Baehr W (1992) Characterization of cDNA clones encoding the mouse blue pigment. ARVO abstracts. Invest Ophthalmol Vis Sci 33:1004.

Naash MI, Ripps H, Li S, Goto Y, Peachey NS (1996a) Polygenic disease and retinitis pigmentosa: albinism exacerbates photoreceptor degeneration induced by the expression of a mutant opsin in transgenic mice. J Neurosci 16:7853-7858.

Naash MI, Li S, Roveri L, Peachey NS, Wu T (1996b) Photoreceptor degeneration associated with the expression of a G90D mutation in the opsin gene. ARVO abstracts. Invest Ophthalmol Vis Sci 37:S698.

Nakazawa M, Kikawa E, Kamio K, Chida Y, Shiono T, Tamai M (1994) Ocular findings in patients with autosomal dominant retinitis pigmentosa and transversion mutation in codon 244 (Asn244Lys) of the peripherin/rds gene. Arch Ophthalmol 112:1567-1573.

Nichols BE, Drack AV, Vandenburgh K, Kimura AE, Sheffield VC, Stone EM (1993a) A 2 base pair deletion in the RDS gene associated with butterfly-shaped pigment dystrophy of the fovea. Hum Mol Genet 2:601-603.

Nichols BE, Sheffield VC, Vandenburgh K, Drack AV, Kimura AE, Stone EM (1993b) Butterfly-shaped pigment dystrophy of the fovea caused by a point mutation in codon 167 of the RDS gene. Nat Genet 3: 202-207.

Nir I, Agarwal N, Papermaster DS (1990) Opsin gene expression during early and late phases of retinal degeneration in $r d s$ mice. Exp Eye Res 95:223-233.
Peachey NS, Goto Y, Al-Ubaidi MR, Naash MI (1993) Properties of the mouse cone-mediated electroretinogram during light adaptation. Neurosci Lett 162:9-11.

Peachey NS, Goto Y, Quiambao AB, Al-Ubaidi MR (1995) Functional consequences of oncogene-induced photoreceptor degeneration in transgenic mice. Vis Neurosci 12:513-522.

Pittler SJ, Baehr W (1991) Identification of a nonsense mutation in the rod photoreceptor cGMP phosphodiesterase- $\beta$-subunit of the $r d$ mouse. Proc Natl Acad Sci USA 88:8322-8326.

Pugh Jr EN, Lamb TD (1993) Amplification and kinetics of the activation steps in phototransduction. Biochim Biophys Acta 1141:111-149.

Röhlich P, van Veen T, Szél Á (1994) Two different visual pigments in one retinal cone cell. Neuron 13:1159-1166.

Sanyal S, Dees C, Zeilmaker GH (1986) Development and degeneration of retina in $r d s$ mutant mice: observations in chimaeras of heterozygous mutant and normal genotypes. J Embryol Exp Morphol 98:111-121.

Shady S, Hood DC, Birch DG (1995) Rod phototransduction in retinitis pigmentosa. Distinguishing alternative mechanisms of degeneration. Invest Ophthalmol Vis Sci 36:1027-1037.

Szél Á, Röhlich P, Caffé AR, Juliusson B, Aguirre G, Van Veen T (1992) Unique topographic separation of two spectral classes of cones in the mouse retina. J Comp Neurol 325:327-342.

Travis GH, Bok D (1993) A molecular characterization of the retinal degeneration slow ( $r d s$ ) mouse mutation. In: Retinal degeneration (Hollyfield JG, Anderson EA, LaVail MM, eds), pp 219-230. New York: Plenum.

Travis GH, Brennan MB, Danielson PE, Kozak DA, Sutcliffe JG (1989) Identification of a photoreceptor-specific mRNA encoded by the gene responsible for retinal degeneration slow $(r d s)$. Nature 338:70-73.

Travis GH, Groshan KR, Lloyd M, Bok D (1992) Complete rescue of photoreceptor dysplasia and degeneration in transgenic retinal degeneration slow $(r d s)$ mice. Neuron 9:113-119.

Van Nie R, Ivanyi D, Demane P (1978) A new H-2-linked mutation, $r d s$, causing retinal degeneration in the mouse. Tissue Antigens 12:106-108.

Wells J, Wroblewski J, Keen J, Inglehearn C, Jubb C, Eckstein A, Jay M, Arden G, Bhattacharya S, Fitzke F, Bird A (1993) Mutations in the human retinal degeneration slow $(r d s)$ gene can cause either retinitis pigmentosa or macular dystrophy. Nat Genet 3:213-218.

Wilkie AOM (1994) The molecular basis of genetic dominance. J Med Genet 31:89-98.

Wroblewski JJ, Wells III JA, Eckstein A, Fitzke FW, Jubb C, Keen TJ, Inglehearn CF, Bhattacharya SS, Arden GB, Jay MR, Bird AC (1994) Ocular findings associated with a 3 base pair deletion in the peripherinRDS gene in autosomal dominant retinitis pigmentosa. Br J Ophthalmol 78:831-836. 